\title{
Efficacy of Distraction on Pain Relief during Lumber Puncture in Children with Leukemia at South Egypt Cancer Institute-Assiut University
}

\author{
Shadia Abd Elmonem Syan, Marzoka Abd El-Aziz Gadallah, \& Amany Mohamed Ali. \\ Demonstration of Nursing, Faculty of Nursing, South Valley University Assiut, University \\ Department of Pediatric Oncology, South Egypt Cancer Institute, Assiut University \\ Assistant Professor of Pediatric Oncology, Faculty of medicine, Assiut University
}

\begin{abstract}
Children with leukemia are subjected to pain during various procedures. Distraction is one of the easiest and least costly methods of non-pharmacological pain relief. This study aimed to identify the efficacy of distraction on pain relief during lumber puncture in children with leukemia. Methods: A quasi experimental research design conducted among 90 patients at South Egypt Cancer Institute - Assiut University. children were allocated to either breathing, colored cards, or control group, thirty child for each group .Two tools were used, Tool one: Structured interview sheet to collect socio - demographic data and tool two where children's pain was assessed by FLACC scale. Findings: Pain score in the breathing and colored cards groups was highly significantly lesser than the control group. There was no significant difference between the two sexes while as the age increases, the tolerance to pain increases too. Conclusion: This study showed that breathing exercises and colored cards can significantly reduce the pain of intrathecal injection. Recommendations: Considering the key role of nurses in a health care team, the researchers hope that the results of this study can help them learn this method and implement it in hospitalized children who undergo painful procedures.
\end{abstract}

\section{Key words: Breathing Exercises; Colored Cards; Intrathecal Injection; Pain; Leukemia \& Children}

\section{Introduction}

Leukemia is a group of blood cancers that affects bone marrow and results in uncontrolled accumulation of abnormal (malignant) blood cells. The accumulation of malignant cells interferes with the body's production of normal blood cells and can result in severe anemia, decreased ability to fight infections and a predisposition to bleeding. Leukemia accounts for about one third of childhood cancer (Zupanec and Tomlinson, 2010 \& Sanzhar, 2007) Leukemia may be classified as acute or chronic, lymphocytic or myelogenous. Acute leukemias are rapidly progressive diseases affecting the undifferentiated or immature cells; the result is cells without normal function. Chronic leukemias progress more slowly, permitting maturation and differentiation of cells so that they retain some of their normal function (Colby-Graham and Chordas, 2003)

Pain is a highly individualized, subjective experience that can affect any person of any age. It is a complex phenomenon that involves multiple components and is influenced by a myriad of factors. Pain has been often described as a subjective experience that involves both sensory and emotional factors. Pain is defined by the International Association for the Study of Pain as" an unpleasant sensory and emotional experience that is associated with actual or potential tissues damage"(IASP, 2007).
Pain is a major source of distress for children and their families as well as health care providers. Children may experience pain as a result of surgery, injuries, acute and chronic illnesses, and medical or surgical procedures. Inadequately managed pain can lead to serious physical and emotional consequences such as increased oxygen consumption and alterations in blood glucose metabolism. In addition, the experience of untreated pain early in life may lead to long term physiologic, psychological, and behavioral consequences for the child (Hockenberry et al ., $2011 \&$ Bowden and Greenberg, 2008).

Many childhood leukemias require frequent painful procedures as part of diagnosis, treatment, and reassessment. A child with acute lymphocytic leukemia receives, depending on the chemotherapy protocol, lumbar punctures (LP) with intrathecal chemotherapy twice in the first month after diagnosis and 4 to 6 times for the next 2 months. This is repeated several times throughout consolidation and maintenance phases of chemotherapy, which can last 2 to 3 years. Although children can tolerate these procedures with topical anesthesia, physical restraint, and sedation, this process inflicts considerable distress, anxiety, depression, and pain for patients and families (Von Heijne et al., 2004).

Pediatric patients often refer to those procedures as the most painful episodes they experienced during the course of their malignancy treatment (Zernikow et 
al., 2005). Thus, the nurse should be able to manage painful procedures while reducing emotional and physical effects of painful procedures and avoiding long-term results of pain in children. (Hasanpour et al., 2006) Consequently, there are many different approaches to the treatment of procedural pain and anxiety of children during medical procedures, including pharmacological and non-pharmacological methods (Taddio et al., 2010).

The role of non pharmacologic techniques, such as distraction and guided imagery, in alleviating pain and anxiety has been well documented in pediatric oncology patients undergoing frequent invasive medical procedures and also in children with other recurrent painful conditions. Distraction is a simple, cognitive behavioral intervention that diverts attention from a stressful stimulus and focuses it onto a more pleasant one. To be effective, the distraction technique must be age appropriate, and it must be appealing to the recipient (Ball et al., 2003).

The nurse's role in assisting patients with non pharmacologic interventions for procedural pain is to evaluate the appropriateness of their use for the procedure, determine the patient's willingness and readiness to use them, teach the patient's how to use the available options, support and reinforce correct use before, during, and after the procedure, and evaluate and document the effectiveness of the activity (Friesner et al., 2006 \& Gatlin and Schulmeister, 2007)

\section{Significance of the study}

There are many studies conducted to evaluate the efficacy of interactive methods of distraction. Although distraction cards can be used for pain relief but there is no data to prove that distraction cards is effective on pain relief of children. Therefore, this study assesses the effect of distraction cards on pain relief of children with leukemia compared to breathing exercise during lumber puncture procedure.

\section{Aim of the study}

The aim of this study was to identify the efficacy of distraction on pain relief during lumber puncture in children with leukemia.

\section{Research Question}

1- Do Children who practice deep breathing exercise experience less pain than those who are receiving routine hospital care?

2-Do Children who practiced distraction in the form of looking through colored cards experience less pain than those who are receiving routine hospital care?

\section{Subjects and Method}

\section{Research design}

A quasi - experimental research design was used to conduct this study.

\section{Setting}

The present study was conducted in Pediatric Oncology Department (POD) at South Egypt Cancer Institute- Assiut University.

Subjects: this study included a convenient sample of 90 child patients who were selected from the previous setting. They were randomly divided into three groups (30 in each group):

Group I for applying deep breathing exercises.

Group II for using colored cards.

Group III for the control group who were receiving the hospital routine.

The criteria for the selection of the study subjects were as follow

1 -Both sexes.

2-Children more than three years of age.

3-Children diagnosed with leukemia.

4- Children undergoing intrathecal chemotherapy treatment (in the induction, consolidation, or maintenance phases) via invasive procedure (lumber puncture).

\section{Exclusion criteria were}

1-Children diagnosed with disease other than leukemia.

2-Children receiving analgesia.

Tools

Two tools for collecting data were used in this study:

Tool one: "Children and parents profile structured questionnaire"

It was developed by the researcher after reviewing the related literature and it consisted of two parts:

Part I: children Socio-demographic characteristics that included age, sex, birth date, and residence: and socio-demographic characteristics of the children parents that included age, education, and occupation.

Part II: Children clinical data that included onset of disease, type of leukemia, and phase of chemotherapy.

Tool two: "Children pain assessment scale (FLACC scale)"

This tool was developed by (Merkle et al., 1997), it was used to assess child's pain. This tool measures five parameters: facial expression, legs, activity, cry, and consol ability. The score ranged from $(0=$ no pain to $10=$ worst pain).

\section{Scoring system:}

$0=$ no pain $\quad 1-3=$ mild pain $\quad 4-6=$ moderate pain $7-10=$ sever pain

Method

1. Official Permission was obtained from the director of the south Egypt Cancer institute - Assiut University.

2. Written consent from parents of studied children was obtained. 
3. Tool one was developed by the researcher after reviewing literature.

4. Tool two was developed by Merkle et al., (1997).

5 . Tool one was tested for its validity by 5 experts in the pediatric field where its value was 0.93 .

6. Reliability of the tool was estimated by Alpha Cronbach' $\mathrm{s}$ test for tool one and its value was $\mathrm{R}=0.86$.

7. Reliability of tool two was assessed in previous study done by Lwuiz et al., (2002) with reliability of $r=88 \%$.

8. A pilot study was carried out on 9 children $(10 \%$ of the subjects) to test the feasibility and applicability of the tools. Necessary modification was done. They were excluded from the sample.

9. Confidentiality of the researcher was asserted. Explanation of the aim and methodology of the study was done to children's parents by the researcher. The right to refuse to participate in the study was emphasized to the children's parents.

Data collection

-Assessment of socio-demographic characteristics of children and their parent's conditions was done by the researcher through using tool one (part I) for all three groups (study groups and control group).

-Children's pain was assessed by the researcher during the invasive procedure (Lumber puncture) by using children's pain assessment scale (FLACC scale).

-The children in control group followed the routine hospital care in receiving intrathecal chemotherapy via lumber puncture procedure.

-The researcher applied diaphragmatic breathing exercises for group one during invasive procedure (lumber puncture).

- The researcher gave colored cards to group two during invasive procedure (lumber puncture).

- Data were collected during the period from the beginning of December 2012 to the end of December 2013; each questionnaire was filled throughout 15 minutes.

\section{Statistical analysis}

Data were collected, tabulated and analyzed. Data entry was done using compatible personal computer (Microsoft Excel 2007 computer soft ware package), while statistical analysis was done using SPSS 16.0 statistical software package and Excel for figures. The content of each tool was analyzed, categorized and then coded. Data were presented using descriptive statistics in the form of frequencies and percentages for qualitative variables and mean and standard deviations for quantitative variables.

Qualitative variables were compared using Chisquare and ANOVA tests. Statistical significance was considered at $\mathrm{P}$-value $<0.05$.

Table (1): Frequency distribution of the studied children according their socio-demographic characteristics.

\begin{tabular}{|l|r|r|}
\hline \multicolumn{1}{|c|}{ Items } & \multicolumn{2}{c|}{ No. } \\
\hline Age of child & 39 & 43.3 \\
\hline 3- $\downarrow$ years & 29 & 32.2 \\
\hline 6- $\downarrow 10$ years & 22 & 24.4 \\
\hline $10-15$ years & \multicolumn{2}{|c|}{$7.1+3.5$} \\
\hline Mean age & \multicolumn{2}{|c|}{} \\
\hline Sex & 55 & 61.1 \\
\hline Male & 35 & 38.9 \\
\hline Female & & \\
\hline
\end{tabular}

Table (2): Frequency distribution of the studied children according their clinical data.

\begin{tabular}{|c|c|c|}
\hline Items & No. & $\%$ \\
\hline \multicolumn{3}{|l|}{ 1. Type of leukemia } \\
\hline ALL & 79 & 87.8 \\
\hline AML & 11 & 12.2 \\
\hline \multicolumn{3}{|l|}{ 2-Duration of Leukemia } \\
\hline$\downarrow 1$ year & 61 & 67.8 \\
\hline $1-\downarrow 2$ year & 21 & 23.3 \\
\hline 2-3year & 8 & 8.9 \\
\hline \multicolumn{3}{|l|}{ 3-Phase of chemotherapy } \\
\hline Induction & 40 & 44.4 \\
\hline Consolidation & 27 & 30 \\
\hline Maintenance & 23 & 25.6 \\
\hline
\end{tabular}


Table (3): Comparison between the children according the degree of pain (FLACC scale) in the study group (I) and the control group (III) as regard to their age groups during intrathecal chemotherapy administration.

\begin{tabular}{|c|c|c|c|c|c|c|c|c|c|c|c|c|c|}
\hline \multirow{4}{*}{ Age of child } & \multirow{2}{*}{\multicolumn{6}{|c|}{$\frac{\text { Group I }}{\text { Breathing }}$}} & \multirow{2}{*}{\multicolumn{6}{|c|}{$\frac{\text { Group III }}{\text { Control }}$}} & \multirow{4}{*}{ P. Value } \\
\hline & & & & & & & & & & & & & \\
\hline & \multicolumn{2}{|c|}{ Mild } & \multicolumn{2}{|c|}{ Moderate } & \multicolumn{2}{|c|}{ Severe } & \multicolumn{2}{|c|}{ Mild } & \multicolumn{2}{|c|}{ Moderate } & \multicolumn{2}{|c|}{ severe } & \\
\hline & No & $\%$ & No & $\%$ & No & $\%$ & No & $\%$ & No & $\%$ & No & $\%$ & \\
\hline $3-\downarrow 6$ years & 1 & 50 & 1 & 50 & 0 & 0.0 & 0 & 0.0 & 1 & 5.2 & 18 & 94.8 & $0.001 * *$ \\
\hline 6- $\downarrow 10$ years & 14 & 93.3 & 1 & 6.7 & 0 & 0.0 & 0 & 0.0 & 2 & 33.3 & 4 & 66.7 & $0.001 * *$ \\
\hline $\begin{array}{c}10-15 \\
\text { years }\end{array}$ & 13 & 100 & 0 & 0.0 & 0 & 0.0 & 1 & 20 & 4 & 80 & 0 & 0.0 & $0.001 * *$ \\
\hline P. value & \multicolumn{6}{|c|}{0.031} & \multicolumn{6}{|c|}{0.001} & \\
\hline
\end{tabular}

Table (4): Comparison between the children according the degree of pain (FLACC scale) in the study group (II) and the control group (III) as regard to the age groups during intrathecal chemotherapy administration.

\begin{tabular}{|c|c|c|c|c|c|c|c|c|c|c|c|c|c|}
\hline \multirow{4}{*}{$\begin{array}{c}\text { Age of } \\
\text { child }\end{array}$} & \multirow{2}{*}{\multicolumn{6}{|c|}{ Group II }} & \multicolumn{6}{|c|}{ Group III } & \multirow{4}{*}{ P. Value } \\
\hline & \multicolumn{4}{|c|}{ Colored cards } & & & \multicolumn{6}{|c|}{ Control } & \\
\hline & \multicolumn{2}{|c|}{ Mild } & \multicolumn{2}{|c|}{ Moderate } & \multicolumn{2}{|c|}{ Severe } & \multicolumn{2}{|c|}{ Mild } & \multicolumn{2}{|c|}{ Moderate } & \multicolumn{2}{|c|}{ Severe } & \\
\hline & No & $\%$ & No & $\%$ & No & $\%$ & No & $\%$ & No & $\%$ & No & $\%$ & \\
\hline 3- $\downarrow 6$ years & 8 & 44.4 & 7 & 38.9 & 3 & 16.7 & 0 & 0.0 & 1 & 5.2 & 18 & 94.8 & $0.001 * *$ \\
\hline $\begin{array}{l}\text { 6- } \downarrow 10 \\
\text { years }\end{array}$ & 8 & 88.9 & 0 & 0.0 & 1 & 11.1 & 0 & 0.0 & 2 & 33.3 & 4 & 66.7 & $0.003 * *$ \\
\hline $\begin{array}{c}10-15 \\
\text { years }\end{array}$ & 3 & 100 & 0 & 0.0 & 0 & 0.0 & 1 & 20 & 4 & 80 & 0 & 0.0 & $0.050 *$ \\
\hline P. value & \multicolumn{6}{|c|}{0.098} & \multicolumn{6}{|c|}{0.001} & \\
\hline
\end{tabular}

Table (5): Comparison between the children according the degree of pain (FLACC scale) in the studied groups (I) and (II) as regard their age groups during intrathecal chemotherapy administration.

\begin{tabular}{|c|c|c|c|c|c|c|c|c|c|c|c|c|c|}
\hline \multirow{4}{*}{ Age of child } & \multirow{2}{*}{\multicolumn{6}{|c|}{$\frac{\text { Group I }}{\text { Breathing }}$}} & \multicolumn{6}{|c|}{ Group II } & \multirow{4}{*}{ P. Value } \\
\hline & & & & & & & & & Color & Carc & & & \\
\hline & \multicolumn{2}{|c|}{ Mild } & \multicolumn{2}{|c|}{ Moderate } & \multicolumn{2}{|c|}{ Severe } & \multicolumn{2}{|c|}{ Mild } & \multicolumn{2}{|c|}{ Moderate } & \multicolumn{2}{|c|}{ severe } & \\
\hline & No & $\%$ & No & $\%$ & No & $\%$ & No & $\%$ & No & $\%$ & No & $\%$ & \\
\hline 3- $\downarrow 6$ years & 1 & 50 & 1 & 50 & 0 & 0.0 & 8 & 44.4 & 7 & 38.9 & 3 & 16.7 & 0.818 \\
\hline $6-\downarrow 10$ years & 14 & 93.3 & 1 & 6.7 & 0 & 0.0 & 8 & 88.9 & 0 & 0.0 & 1 & 11.1 & 0.320 \\
\hline $\begin{array}{c}10-15 \\
\text { years }\end{array}$ & 13 & 100 & 0 & 0.0 & 0 & 0.0 & 3 & 100 & 0 & 0.0 & 0 & 0.0 & 0.063 \\
\hline P. value & \multicolumn{6}{|c|}{$0.031 *$} & \multicolumn{6}{|c|}{0.098} & \\
\hline
\end{tabular}

Fig (1): Comparison between the children according the degree of pain (FLACC scale) in the study group (I) and the control group (III) in relation to their phase of chemotherapy during intrathecal chemotherapy

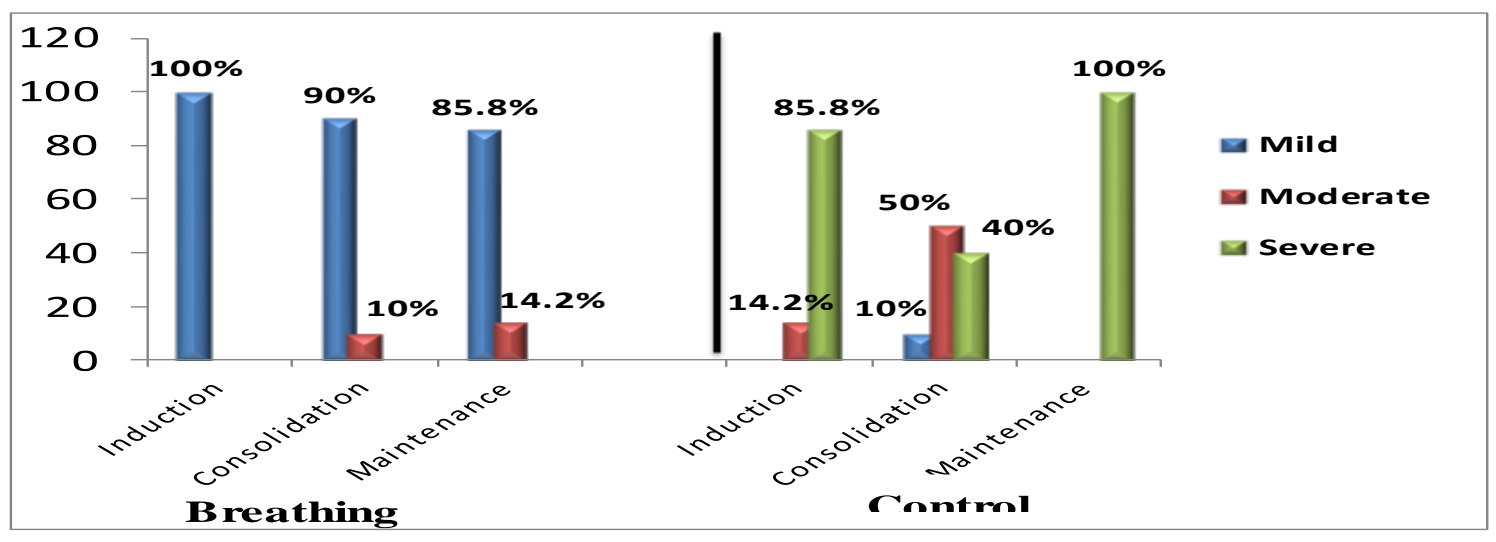

Vol (2) , No (3) , Supplement June 2014 
Fig (2): Comparison between the children according the degree of pain (FLACC scale) in the study group (II) and the control group (III) in relation to their phase of chemotherapy during intrathecal chemotherapy administration.

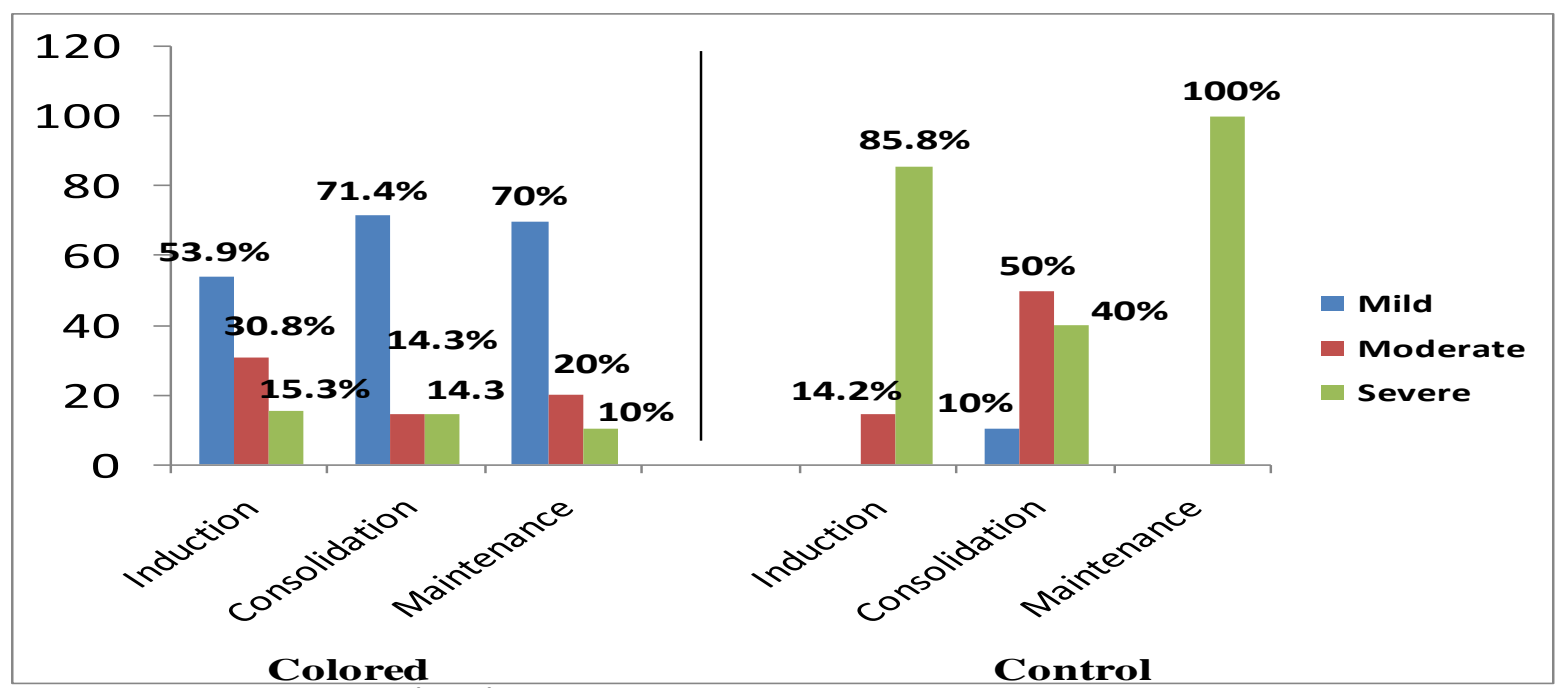

Fig (3): Comparison between the children according the degree of pain (FLACC scale) in the studied groups (I) and (II) in relation to their phase of chemotherapy during intrathecal chemotherapy administration.

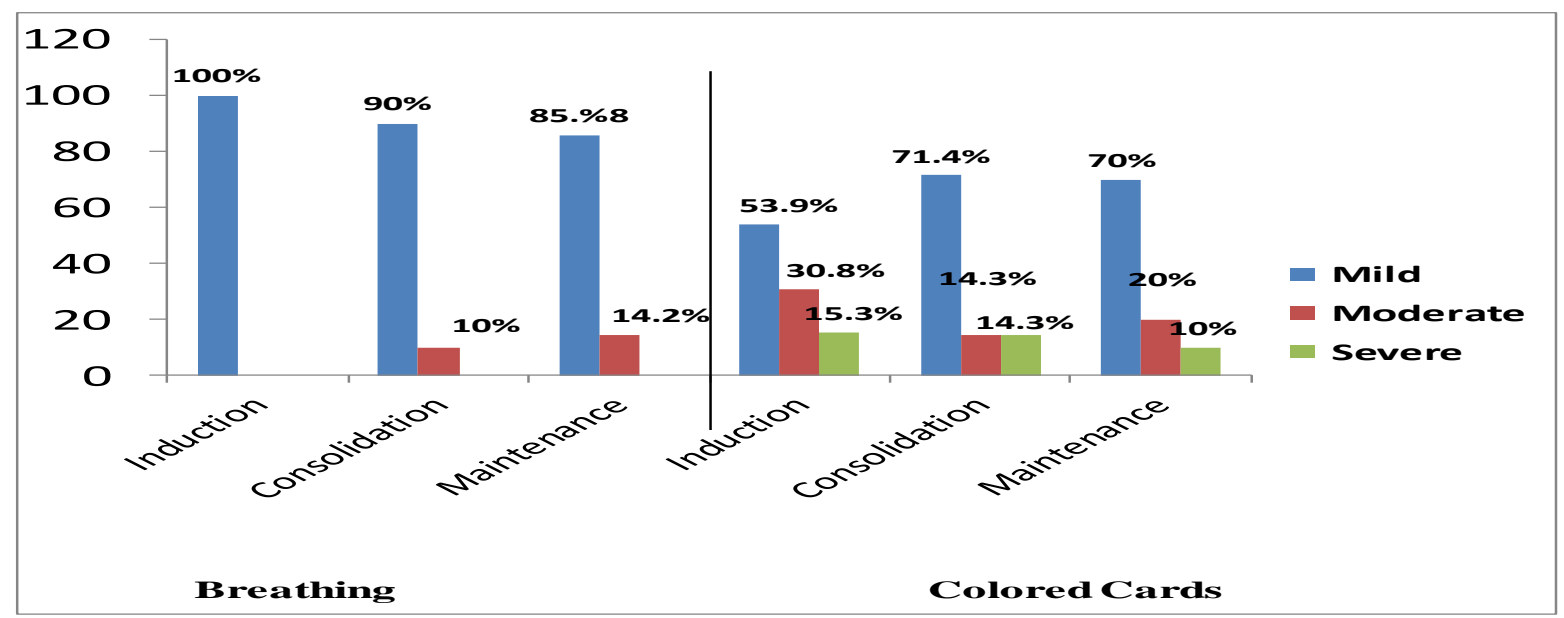

Figure (4): Comparison between the children in the study group I (breathing group) study group II (colored cards group) and Group III (control group) as regard the degree of pain during intrathecal chemotherapy administration.

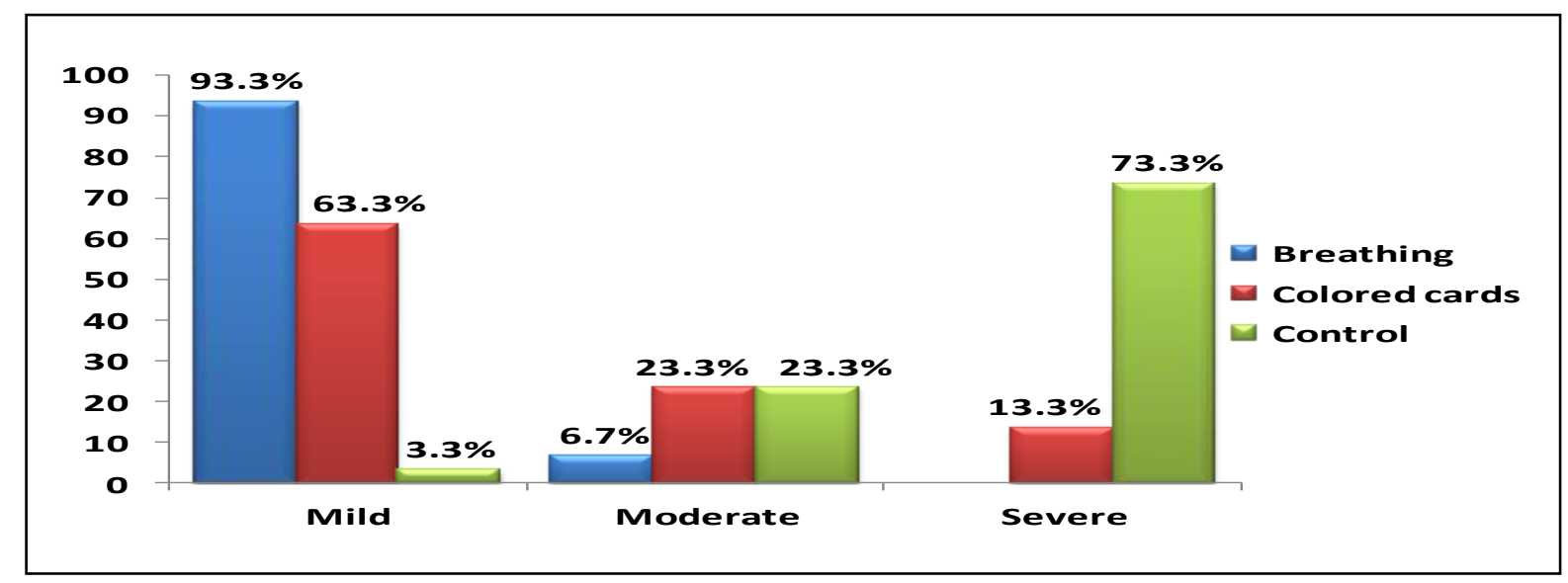

Vol (2), No (3) , Supplement June 2014 
Table (1): Showed the frequency distribution of the studied children regarding their socio- demographic characteristics. It was revealed that less than half of the studied subjects $(43.3 \%)$ were in the age group of (3- $\downarrow 6$ years), while one third of them (32.2\%) were in the age group of (6- $\downarrow 10$ years).The mean age in the three age groups was $(7.1 \pm 3.5)$ years. Also more than one half of the studied subjects $(61.1 \%)$ were male.

Table (2): indicated the frequency distribution of the studied children regarding the clinical data. It was found that the majority of the studied children (87.8\%) were diagnosed with Acute Lymphoblastic Leukemia (ALL) while only $12.2 \%$ of them had Acute Myeloid Leukemia (AML).

It was also noticed from the same table that more than two thirds of the studied children $67.8 \%$ were in the first year of the disease, while only $8.9 \%$ of them were in the 2-3 years of the disease duration. Moreover, less than half of the studied children $44.4 \%$ were in the induction phase of leukemia treatment, while $30 \%$ in the consolidation and $25.6 \%$ in maintenance phases.

Table (3): Presented comparison between the children according the degree of pain in the study group (I) and the control group (III) as regard to their age groups during intrathecal chemotherapy administration. A highly statistical significant difference was found between the breathing exercises and the control groups at the P Value of 0.001 . It was found that half of the studied children $(50 \%)$ at the age group of 3- $\downarrow 6$ years in the breathing exercises group had mild pain compared to none in the control group. Contrary to that, the majority of the children in the control group (94.8\%) had severe pain compared to none of them in the breathing group at the same age group.

It was found that the majority $(93.3 \%)$ of the studied children at the age group of $6-\downarrow 10$ years in the breathing exercises group had mild pain compared to none in the control group. In contrast, $66.7 \%$ of the children in the control group had severe pain compared to none in the breathing exercises group at the same age group. Finally, all of the children $(100 \%)$ at the age group of $10-15$ years in the breathing exercises group had mild pain compared to only $20 \%$ in the control group. Contrary to that $80 \%$ of children in the control group had moderate pain compared to none in the breathing group, also none of the children in the both groups had no pain in the all age groups.

Table (4): Illustrated the comparison between the children according the degree of pain in the study group (II) and the control group (III) as regard to the age groups during intrathecal chemotherapy administration. It was revealed that a highly statistical significant difference was found between the colored cards and the control groups.

It was found that $44.4 \%$ of children at the age group of $3-\downarrow 6$ years in the colored cards group had mild pain compared to none of them in control group. In contrast, the majority $(94.8 \%)$ of the studied children in the control group had severe pain compared to $16.7 \%$ of them in the colored cards group at the same age group where the P. Value $=0.001 * *$. While 88.9 $\%$ of children at the age group of (6- $\downarrow 10$ years) in the colored cards group had mild pain compared to none of them in the control group. Contrary to that $66.7 \%$ of children in the control group had severe pain compared to $11.1 \%$ of them in the colored cards group at the P. Value of $0.001 * *$. It was also found that all of children (100\%) at the age group of 10-15 years in the colored cards group had mild pain compared to only $20 \%$ of them in the control group at the P. Value of $0.050^{*}$. None of the studied children in both groups had no pain in the all age groups.

Table (5): Presented the comparison between the children according the degree of pain in the studied group (I) and (II) as regard their age groups during intrathecal chemotherapy administration. It was revealed that no statistical significant difference was found between the breathing and colored cards groups. None of the children in the both groups had no pain in the all age groups.

Fig (1): Showed the comparison between the children according the degree of pain in the study group (I) and the control group (III) in relation to their phase of chemotherapy during intrathecal chemotherapy. It was revealed that a highly statistical significant difference of the children total pain scores in the breathing and control groups during intrathecal chemotherapy administration in relation to their induction, consolidation, and maintenance phases of treatment at the P. Value of $0.001 * *$.

In the induction phase: it was found that all of the studied children $100 \%$ in the breathing group had mild pain compared to none of them in the control group, contrary to that, $14.2 \%$ and $85.8 \%$ respectively of the children in the control group had moderate and severe pain compared to none of them in the breathing group.

In the consolidation phase: The majority of children (90\%) in the breathing group had mild pain compared to only $10 \%$ of them in the control group. Contrary to that, $40 \%$ of the children in the control group had severe pain compared to none of them in breathing group. In maintenance phase: $85.8 \%$ of the children in the breathing group had mild pain compared to none of them in the control group. In contrast, all of children (100\%) in the control group had severe pain compared to none of them in the breathing group. 
None of children in the both groups had no pain degree.

Fig(2): Demonstrated the comparison between the studied children according the degree of pain in the study group (II) and the control group (III) in relation to their phase of chemotherapy during intrathecal chemotherapy administration. It was revealed ta highly statistical significant difference between the children in the total pain scores in the colored cards and the control groups at P. Value of $\left(0.001^{* *}, 0.001 * * \& 0.002^{* *}\right)$ respectively.

In the induction phase: It was found that $53.9 \%$ of the children in the colored cards group had mild pain compared to none of them in the control group. Contrary to that, the majority $(85.8 \%)$ of the children in the control group had severe pain compared to only $15.3 \%$ of them in the colored cards group. In the consolidation phase: $71.4 \%$ of the children in the colored cards group had mild pain compared to $10 \%$ of them in the control group. In contrast, $40 \%$ of the children in the colored cards group had severe pain compared to $14.3 \%$ of them in the control group. While in the maintenance phase: about $70 \%$ of the children in the colored cards group had mild pain compared to none of them in the control group. Contrary to that all the children (100\%) in the control group had severe pain compared to only $10 \%$ of them in the colored cards group. It was also noticed that none of children the both groups had no pain.

Fig (3) indicated the comparison between the studied children according the degree of pain in group (I) and (II) in relation to their phase of chemotherapy during intrathecal chemotherapy administration. It was revealed a statistically significant difference between the children total pain scores that was found in the breathing and colored cards groups during intrathecal chemotherapy administration in relation to their induction phase of chemotherapy treatment at the P. Value of $\left(0.020^{*}\right)$. Moreover, it was found that all of children (100\%) in the breathing group had mild pain compared to $53.9 \%$ in the colored cards group. Contrary to that, $15.3 \%$ of the children in the colored cards group had severe pain compared to none in the breathing group.

The current results also revealed that no significant difference was found between the children in the pain scores in the breathing and colored cards groups in relation to their consolidation and maintenance phases, but the children had lower pain scores in the breathing group than those in the colored cards group, it was found that $14.3 \%$ of the children in the colored cards group had equally moderate and severe pain compared to none of them in the breathing group. While $10 \%$ of children in the colored cards group at the maintenance phase had severe pain compared to none of them in breathing group. None of the children in the both groups had no pain.

\section{Discussion}

In the past, the major focus on pediatric pain research has centered on pharmacologic strategies for pain management. In contrast, the literature published between 1988-1997, which examined non pharmacologic pain management interventions and studied the use of these interventions by nurses, demonstrated that all of the interventions provided some degree of pain relief Kuppenheimer and Brown., (2002).

The current study adds to the growing body of evidence that supports the benefits of cognitivebehavioral interventions in reducing pain in children and adolescents with leukemia during lumber puncture procedure. The results indicate that children and adolescents who participated in distraction using either breathing or colored cards during their intrathecal chemotherapy administration demonstrated significantly less pain than did comparison participants.

Result of the current study from the comparison between the breathing and control groups revealed that there was a highly significant difference between both groups as regards to pain scores $\left(\mathrm{P}=0.001^{* *}\right)$ It was found that none of children in the breathing group had severe pain compared to more than two thirds $(73.3 \%)$ of them in the control group. This was consistent with Pourmovahed et al., (2013) who revealed that the mean pain intensity score in the breathing study group was (2.98) that was less than that in the control group (3.80). Also it was consistent with Bagheriyan et al., (2011) they reported that the mean pain intensity in breathing group was 0.96 \pm 0.75 while that in the control group was $3.80 \pm 2.80$.

Moreover, this finding is in line with the result of Valizadeh et al., (2004) study, they reported that pain intensity in routine venous puncture is moderate while it is low in breathing group. These results also were in agreement with Broome et al., (1998), they used regular breathing technique on children with cancer at the time of pulling CSF and the pain was significantly reduced. Furthermore these results were supported by Pederson (1994) who studied the effect of bubble-blowing during the injection, found that blowing bubbles helps the child breathe more deeply and exhale slowly which promotes relaxation. On the contrary, (French et al., 1994) evaluated the efficacy of blowing out air with 75 participants; the results of meta-analysis indicated that this intervention was not efficacious in reducing self-reported pain or behavioral distress. 
Result of the current study indicated a highly significant difference from the comparison between the two groups (colored cards and control groups) as regard pain scores $(\mathrm{P}=0.001 * *)$ It was found that $(13.3 \%)$ of children in colored cards group had severe pain compared to more than two thirds $(73.3 \%)$ of them in control group ,this was consistent with Inal and Kelleci, (2012) they found that colored cards group had significantly lower pain levels than the control group during blood drawing procedure. Contrary to Carlson et al., (2000) who found that children and adolescents undergoing venipuncture or IV insertion reported no differences in feeling pain, fear, or distress in the distraction-kaleidoscope group and the control group.

Finding of the present study showed that although both methods of practicing deep breathing exercise and looking through colored cards reduced children's pain significantly, It was found a significant difference between the two distraction methods where active distraction of practicing deep breathing exercises was more effective than passive distraction this was consistent with Legrain et al., (2009) who stated that neurocognitive models of pain which focus on tasks that involve central executive functioning and/or more deliberate, rather than automatic, regulation of attention should be more effective in combating pain than passive tasks that require less central cognitive resources. Also this was consistent with the studies of Dahlquist et al., (2007) and Mason et al., (1999) who demonstrated that interactive distraction, which requires the child to cognitively engage with the distracting stimulus is more effective than passive distraction, which only requires the child to visually or auditory observe the distracting stimulus.

Moreover, finding of the present results revealed that the age group 3-6 years old of children in the breathing group experienced less pain scores than the same age group in the control group during intrathecal chemotherapy administration. This was consistent with Peretz and Gluck, (1999) who revealed that participants who aged from 3-7 years old in the breathing group demonstrated less pain than the control group. Also this was supported by Sparks (2001) who found that active (bubble blowing) on 105 participants aged 4-6 years old is significantly effective in reducing perceived pain.

The current results revealed that the three distributed age groups in the range of 3-15 years in colored cards group experienced less pain score than the same age groups in control group. This was consistent with Vessey et al., (1994) who stated that a visual distractor (kaleidoscope) was found to reduce significantly venipuncture pain in a sample of 100 children ages 3.5 to 12 years. Moreover, in the present study, there was a significant reverse relationship between the age and the pain degree in the breathing group when compared to control group during intrathecal injection, where older children demonstrated superior pain tolerance overall. This was consistent with pourmovahed et al., (2013) who showed that the children aged above 10 years, has less significantly pain intensity than children aged below 10 years during intrathecal injection.

The current study revealed a significant reverse relationship between the age and the pain degree in the colored cards group when compared with control group during intrathecal injection, where older children demonstrated superior pain tolerance overall, this was supported by Pourmovahed et al., (2008) who studied the effectiveness of music on venous puncture pain in children, it was observed that the mean pain intensity in the 10-12 year age group in the both study and control groups was less than that in the other age groups 6-9 years old, this was consistent with Arden (2006) who believed that age is an effective factor in the severity of pain and as the age increases, the tolerance to pain increases too. Also Craig (2002) stated that the intensity of pain behavior during invasive procedures decreases as the age of the child increases. In addition, Arts et al., (1994) stated that younger aged children report more pain intensity than older children irrespective of the interventional method.

It can be explained that cognitive level typically increases with age, thereby influencing the child's understanding of the pain and its impact and his or her choices for coping strategies. In addition, as the child's cognitive level increases, his or her ability to communicate information about pain increases.

The current study revealed that the children demonstrated significantly low pain scores in the breathing and colored cards groups than those in control group during intrathecal injection along their induction, consolidation, and maintenance phases of treatment. It's appears that cognitive energies of the subjects in the breathing group appear to have been successfully occupied by the breathing counting, hand movement over the diaphragm, and sounds of exhaled breath through pursed lips, leaving less energy to interpret the sensory and affective components of pain also looking at various colored cards capture child's attention away from painful procedure.

The current results indicated that children in the breathing group demonstrate less pain score than those in the colored cards group during intrathecal injection at the induction phase. These findings were supported by Broom et al., (1990) who found that children reporting significantly less pain when using more active forms of pain relief. Also 
children in colored cards group demonstrated significantly more pain scores during induction phase of intrathecal chemotherapy than those in consolidation and maintenance phases. It can be explained that the child identifies pain based on his or her experiences with pain in the past, number of episodes of pain, the type of pain, the severity or intensity of the previous pain experience, while induction phase of intrathecal chemotherapy involves intensive treatment, children receives their first intrathecal injection via lumber puncture procedure so that children in this phase have less pain experiences.

In contrast, some passive forms of distraction are touted as more effective than active strategies because the requirement for engagement in active distraction can be challenging for some children experiencing pain and distress Bellieni et al .,(2006); Ma cLaren and Cohen (2005). Furthermore, on the contrary of the current results Esmaeili et al., (2008) and Valizadeh et al., (2004) compared two methods of breathing exercise (active distraction) and music (passive distraction) they found that although both methods reduced children's pain significantly, the effect of music was more effective than the breathing exercise.

Mac Learn and Cohen (2005) indicated also that active forms of distraction may be too demanding for children experiencing pain, whereas a passive technique may be more effective. However, empirical findings are mixed, with some studies finding, no differences between interactive and passive distraction Weiss et al., (2011).

\section{Conclusion}

The total pain scores of the children who were applying distraction methods were significantly lower than those who were receiving routine unit care while age is an effective factor in the severity of pain and as the age increases, the tolerance to pain increases too.

\section{Recommendations}

1-Health care professionals should use appropriate types of distraction methods (diaphragmatic breathing exercises and colored cards) to reduce children's pain during lumber puncture procedures.

2-The use of distraction methods such as diaphragmatic breathing exercises and colored cards are simple, non invasive and effective methods in pain management for pediatric oncology patients undergoing invasive procedures (lumber puncture).

3-Increasing the likelihood of use of distraction methods should be accepted as routine interventions for pain management in Pediatric Oncology Department (POD).

4- Educational programs should be provided to increase the skills of health care professionals in applying distraction methods as a pain management in children during lumber puncture procedures.

5-This study should be replicated and expanded to include a larger sample, focusing on outcomes with different children populations undergoing a variety of procedures in various settings.

\section{References}

1. Arden D., Stacy M., Lough E., (2006): Thelan's Critical Care Nursing. Diagnosis and management. $5^{\text {th }}$ ed., Mosby, Philadelphia, Pp. 185-93.

2. Arts E., Abu-Saad H., Champion D., (1994): A., gerelated Response to lidocaine-prilocaine (EMLA) Emulsion and Effect of Music Distraction on the Pain of Intravenous Cannulation. Pediatrics Journal , 93(5):797-801.

3. Bagheriyan S., Borhani F., Abbaszadeh A., \& Ranjbar H., (2011): The Effects of Regular Breathing Exercise and Making Bubbles on the Pain of Catheter Insertion in School Age Children. Nursing and Midwifery Research Iran Journal, 16(2):174-80.

4. Ball M., Shapiro E., Monheim J., \& Weydert A., (2003): A pilot Study of the use of Guided Imagery for the Treatment of Recurrent Abdominal Pain in Children. Clinical Pediatric Journal, 42: 527-32.

5. Bellieni V., Cordelli M., Raffaelli M., Ricci B, Morgese G., \& Buonocore G., (2006): Analgesic effect of Watching TV during Venipuncture . Archives of Disease in Childhood, 91: 1015-17.

6. Bowden R., \& Greenberg S., (2008): Pediatric Nursing Procedures. $2^{\text {nd }}$ ed., Lippincott Williams\& Wilkins, Philadelphia.

7. Broome E., Rehwaldt M., \& Fogg L., (1998): Relationships between Cognitive Behavioral Techniques, Temperament, Observed Distress, and Pain Reports in Children and Adolescents during Lumbar Puncture. Pediatric Nursing Journal, 13(1):48-54.

8. Broome E., Lillis P., Gahee W., \& Bates T., (1992): The use of Distraction and Imagery with Children during Painful Procedures. Oncology Nursing Forum, 19: 499-502.

9. Broome E., Bates T., Lilis P., \& M., Gahee T., (1990): Medical Fears, Coping Behaviors, and Pain Perceptions in Children during Lumber Puncture. Oncology Nursing Forum, 17 (3):361-70. 
10. Carlson L., Broome E., \& Vessey A., (2000): Using Distraction to reduce Reported Pain, Fear, and Behavioral Distress in Children and Adolescents: A multi-site Study. Society of Pediatric Nursing Journal, 5(2):75-85.

11. Colby-Graham F., \& Chordas C., (2003): The Childhood Leukemias. Pediatric Nursing Journal, 18(2): 87-95.

12. Craig D., (2002): Pain in Infants and Children. Socio developmental variations on the theme, $10^{\text {th }}$ ed., Seattle, California, Pp.305-14.

13. Dahlquist M., McKenna D., Jones K., Dillinger L., Weiss E\& Ackerman S (2007): Active and Passive Distraction using A headmounted Display Helmet: Effects on Cold Pressor Pain in Children. Health Psychology Journal, 26(6): 794-801.

14. Esmaeli K., Iran Far H., Afkari B., \& Abasi P (2008): Comparing the Efficacy of Breathing Exercises and Music to Reduce Pain during the Administration of Blood Vessels Determined. FaslnameBehbood, 12(2):129-39.

15. French M., Painter C., \& Coury L., (1994): Blowing away Shot Pain: A technique for Pain Management during Immunization. Pediatrics Journal, 93: 384-88.

16. Friesner A., Curry M., \& Moddeman R., (2006): Comparison of two Pain Management Strategies during Chest Tube Removal: Relaxation Exercise with Opioids and Opioids alone. Heart Lung Journal, 35: 269-76.

17. Gatlin C., \& Schulmeister L., (2007): When Medication is not enough: Non pharmacologic Management of Pain. Oncology Nursing Clinical Journal, 11(5): 699-704.

18. Hasanpour M., Tootoonchi M.,\& Aein F., (2006): The Effects of two Non pharmacologic Pain Management Methods for Intramuscular Injection Pain in Children. Acute Pain Journal, $8(1): 7-12$.

19. Hockenberry J., Kathy C., Olga T., Meredith S, Quinn F., Chrystal L., \& Laura T., (2011): Managing Painful Procedures in Children with Cancer. Pediatric Hematology/Oncology Journal, 33 (2): 119-27.

20. Inal S., \& Kelleci M., (2012): Distracting Children during Blood Draw: Looking through Distraction Cards is Effective in Pain Relief of Children during Blood Draw. Nursing Practice International Journal, 18:21019.

21. International Association for the Study of Pain (2007): IASP Pain Terminology. Retrieved from: http://www.iasp-pain.org/.

22. Kuppenheimer G., \& Brown T., (2002): Painful Procedures in Pediatric Cancer: A component of
Interventions. Clinical Psychological Review, 22: 753-86.

23. Legrain V., VanDamme S., Eccelston C., Davis K., Seminowicz D., \& Crombez G., (2009): A neurocognitive Model of Attention to Pain: Behavioral and Neuro imaging Evidence. Pain Journal, 144:230-32.

24. Lozano R., (2012): "Global and regional mortality from 235 causes of death for 20 age groups in 1990 and 2010: A systematic Analysis for the Global Burden of Disease Study 2010". Lancet Journal, 380 (9859): 2095-128.

25. Mac Laren E.,\&Cohen L., (2005): A., comparison of Distraction Strategies for Venipuncture Distress in Children. Pediatric Psychology Journal, 30 (5):387-96.

26. Mason S., Johnson H.,\&Woolley C (1999): A., comparison of Distractors for Controlling Distress in Young Children during Medical Procedures. Clinical Psychology in Medical Settings Journal, 6: 239-48.

27. Pederson C., (1994): Ways to feel Comfortable: Teaching Aids to Promote Children's Comfort. Issues in Comprehensive Pediatric Nursing Journal, 17: 37-46

28. Peretz B., \&Gluck M., (1999): Assessing an active Distracting Technique for Local Anesthetic Injection in Pediatric Dental Patients: Repeated Deep Breathing and Blowing out Air. Clinical Pediatric Dentistry Journal, 24:58.

29. Pourmovahed Z., Dehghani K., \& Sherafat A., (2013): Effectiveness of Regular Breathing Technique (Hey-Hu) on Reduction of Intrathecal Injection Pain in Leukemic Children: A Randomized Clinical Trial. Pediatric Iran Journal, 23(5):564-68.

30. Pourmovahed Z., Salimie T., Dehghani K., Yassinie M., Shakiba M., \& Tavangar H (2008): Comparative Study of the Effect of Music Distraction and Emla cream on Pain of the Children during Intravenous Cannulation Nursing Research Iran Journal, 21(55):47-53.

31. Sanzhar A., (2007): "Effects of Individualized Prescriptive Exercise Program on Selected Fitness Parameters and Fatigue of Acute Leukemia Patients Undergoing Treatment". Master thesis. North Carolina University.

32. Sparks G., (2001): Taking the "ouch" out of Injections for Children: Using Distraction to Decrease Pain .MCN: The American Maternal/Child Nursing Journal, 26:72-78

33. Taddio A., Appleton M., Bortolussi R., Chambers C., Dubey V., \& Halperin S (2010): Reducing the Pain of Childhood Vaccination: An evidence-based Clinical Practice Guideline. 
Canadian Medical Association Journal , 182: 43-55.

34. Valizadeh F., Shahabi M., \& Mehrabi Y., (2004): Comparing the Efficacy Distraction Breathing Exercises and Music. Lorestan University of Medical Sciences Journal, 22(6):43-50.

35. Vessey A., Carlson L.. \& McGill J., (1994): Use of Distraction with Children during An acute Pain Experience. Nursing Research Journal, 43: 369-72.

36. Voepel-Lewis T., Merkel S., Tait R., Trzcinka A\& Malviya S., (2002): The Reliability and Validity of the Face, Legs, Activity, Cry, Consolability Observational Tool as A measure of Pain in Children with Cognitive Impairment. Anesth Analg, 95 (5):1224-29.

37. Von Heijne M., Bredlov B., \& So"derhall S., (2004): Propofol or Propofolal Fentanil Anesthesia for Painful Procedures in the Pediatric Oncology Ward. Pediatric Anesthesia Journal, 14: 670- 75 .

38. Weiss E., Dahlquist M., \& Wohlheiter K., (2011): The Effects of Interactive and Passive Distraction on Cold-pressor Pain in Preschoolaged Children. Pediatric Psychology Journal, 36: 816-26.

39. Zernikow B., Meyerhoff U., \& Michel E., (2005): Pain in Pediatric Oncology: Children's and Parents' Perspectives. Pain Europian Journal, 9:395-406.

40. Zupanec S., \& Tomlinson D., (2010): Leukemia. Pediatric oncology nursing, Springer, New York. Cited in Kyle T., \& Carman S., (2013): Essentials of Pediatric Nursing. Nursing care of the child with a neoplastic disorder. $2^{\text {nd }}$ ed., Lippincott Williams \&Wilkins, Philadelphia, Pp.1044-45. 